\title{
Simple, applied text parsing
}

\author{
MICHAEL M. GRANAAS \\ University of Kansas, Lawrence, Kansas
}

\begin{abstract}
Text parsing for use in linguistic or artificial intelligence research can often be ill-suited for use in other lines of investigation in which simple, problem-specific parsing techniques may be used. This paper describes the development of a simple text parser for use in a specific research setting. The resulting parsing programs are compact enough for easy use on most available miniand microcomputers, while still providing adequate results for some applications such as chunking text into small units for later presentation.
\end{abstract}

The specific case examined here involves parsing text for use in the Rapid Serial Visual Presentation (RSVP) format. The RSVP format involves the serial presentation of single words or short text segments to a single fixed location on a computer screen. This type of presentation allows for precise control over various aspects of the text presentation, such as presentation duration. Prior work in our laboratory suggested that multiword text units were superior to single-word text units for RSVP presentation up to a point of about 20 character spaces. Beyond that point, little or no useful information is extracted from the text (Rayner, 1978). Furthermore, eye movement studies have shown that eye fixations are longer at points where phrase structure indicates that a heavier processing load should exist (Just \& Carpenter, 1980). These results, when taken in combination, suggest that the RSVP format might be improved by providing subjects with text that has been divided into appropriate linguistic units.

In a recent study, Cocklin (1983) compared the readability of text divided into linguistic "idea units" with that of text divided into arbitrary "random" units presented in the RSVP format. The idea units were obtained by having independent raters divide the text into "natural" units. The random units were obtained by having a computer divide the same texts into unconstrained segments of the same average length (i.e., 13 character spaces). Cocklin's subjects were able to use the information preserved in the structured text to improve their comprehension scores as measured by a multiple-choice question answering task.

Cocklin's (1983) study was confounded, however, by the difference in the variability of window sizes in the two conditions, with the structured text being more variable in length. It is possible that the readability of text presented in the random condition benefited from reduced perceptual variability, whereas the readability of text in

This research was partially supported by NIMH Training Grant MH15134-05. The author would like to thank James F. Juola and Timothy D. McKay for their comments on earlier drafts of this work. Reprint requests should be mailed to Michael M. Granaas, Department of Psychology, University of Kansas, Lawrence, KS 66045. the structured condition benefited from linguistic information. Consequently, reduction of window-size variability in the structured-text condition might further have improved comprehension in that condition. Despite this confound of unit variability acting against the linguistic units, Cocklin still obtained results favoring the linguistic units.

The major problem in presenting text as linguistic units in the RSVP condition is not, however, one of unit variability, but one of time. In Cocklin's (1983) study, it was necessary to have four independent raters divide the text into linguistic units. These results were then tabulated, and decisions were made about the final placements of boundaries. After this had been done, the computer text files still required editing so that unit boundaries could be marked for later recognition by the computer. Despite the fact that Cocklin used relatively short passages, each required a great deal of time to be readied for presentation in the RSVP condition. Such a process clearly limits the potential usefulness of RSVP reading by making it clumsy and expensive to prepare text for presentation in the RSVP format. Additionally, due to their periodic nature, text sources such as newspapers and magazines are effectively eliminated from consideration for everyday use in RSVP presentation. It would simply prove to be too clumsy and expensive to prepare these materials for RSVP presentation on a daily, weekly, or monthly basis.

The obvious solution to this problem seemed to be the development of a computerized text parser. Computerized text parsers have been developed in artificial intelligence approaches to natural language comprehension devices (e.g., Winograd, 1972). These differ in their complexity and ability to assign correct syntactic functions to constituents of a sentence. A simple parser would save a great amount of time in preparing texts for RSVP display. Such a parser would need only to divide text into units of near optimal size and structure for RSVP presentation. Since such a parser divides the text into linguistic units only for use by human readers, its linguistic analysis of incoming text would not need to be nearly as extensive as that required by a language comprehension device. Such a system would certainly provide a speed 
advantage over human parsers and could possibly be modified to run on-line so that texts could be parsed during presentation rather than prior to presentation. This would allow computer users the flexibility of selecting the presentation format they prefer for any given text. In addition, the computer could be instructed to use upper and/or lower size restrictions on parsed text to help reduce variability in the length of linguistic units.

The purpose of the research described here was to develop a text-parsing program that would reduce variability in text units presented to subjects and, at the same time, maintain useful linguistic structure.

\section{METHOD}

\section{Apparatus}

The original version of the parser was written and implemented on a PDP-11/03 minicomputer with $12 \mathrm{~K}$ of available RAM, using a FORTRAN IV compiler (see Appendix A for a listing). More recently, the parser has been translated to Pascal and implemented on a Sage II minicomputer under the P-System operating system (see Appendix B for a listing).

\section{Text Parsing Program}

Both versions of the text parser were created to provide parsed text for later use in other research. Text for these experiments was parsed prior to the experiment by means of the computer text parser. Several criteria were established for the development of the parser. The first of these was that text, regardless of subject matter, had to be parsed into linguistic units that corresponded to Cocklin's (1983) "idea units." Second, the text had to meet a maximum size restriction of no more than 20 character spaces per unit. This restriction was placed on unit length because earlier research had indicated that the eye could perceive and extract useful information from a maximum of about 20 characters per fixation (Rayner, 1978). Additional research has shown that comprehension in the RSVP format tends to decrease for windows averaging more than about 15 characters in length (Cocklin, Ward, Chen, \& Juola, 1984). Finally, the parsing program and text up to 9,000 characters in length had to fit within the memory limitations of the computer being used. [Note: This size-limitation restriction did not apply to the Pascal version developed on the Sage II, due to a large amount of available random access memory (RAM)]. Because of possible future use of this program on other machines, the size restrictions were still considered important.

After several possible parsing models were considered, a model similar to one outlined in Psychology and Language (Clark \& Clark, 1977, pp. 59-61) was adopted. This model was selected because of its compatibility with the criteria outlined above. The parser was based on a limited number of function words: determiners, quantifiers, prepositions, pronouns, auxiliary verbs, relative pronouns, complementizers, subordinating conjunctions, and coordinating conjunctions (see Appendix $\mathrm{C}$ for a listing of function words used).

The original version of the parser was implemented as a three-pass subroutine in FORTRAN IV. Since punctuation is a reliable indicator of linguistic structure in a text, the first pass of the parser simply looked for and marked punctuation boundaries.

The second pass of the parser used a function-word algorithm to mark additional phrase boundaries. The algorithm made use of a conditional variable that was set to false when a non-function word was encountered and to true when a function word was encountered. The parser made a left-to-right, word-by-word scan beginning at a previously defined boundary. The first word in a given text segment was scanned to determine whether or not it was a function word. If it was not, a conditional variable was set to false. If it was, the scan continued until a non-function word was found, and then the conditional variable was set to false. When the conditional variable changed from false to true, the computer was instructed to mark the intervening space as a phrase boundary. This procedure was then repeated until a previously defined boundary was encountered.

The third and final pass of the parser ensured that phrase units did not exceed the size restrictions set for RSVP presentation. This pass of the parser counted the number of characters in each phrase unit of text. When that count exceeded the 20-character maximum, the phrase was divided at a point as near to the center of the unit as possible, without splitting a word. If the center of the phrase unit was the exact middle of a word (e.g., the letter " $a$ " in the word "plant"), the phrase was broken prior to the word.

\section{RESULTS AND DISCUSSION}

The resulting parser was flexible enough to parse text on virtually any subject matter. This parser should also be compact enough to be implemented on virtually any of the micro- or minicomputers available today, provided that they have at least $16 \mathrm{~K}$ of 16 -bit RAM or $32 \mathrm{~K}$ of 8 bit RAM, as well as a higher level computer language, such as FORTRAN or Pascal. It also provided phrases that closely approximated (87\% agreement) Cocklin's (1983) idea units, while still resulting in text units that were less variable than those used by Cocklin. (Note: the overall interrater agreement for four raters in Cocklin's study was $90 \%$.) Mean standard deviations were 4.7 and 4.1 characters for Cocklin's idea units and the text-parsing program's units, respectively. A pairwise t test of the standard deviations from common materials in the two parsing conditions showed a significant reduction in variability for text units produced by the text-parsing program $[\mathrm{t}(47)=6.52, \mathrm{p}=.0001]$.

An important result of this work is that it shows that a simple, easily implemented parsing routine can be developed to parse text into linguistic units with a reasonable level of agreement $(87 \%)$ with human parsers. Since 
the parser can easily be modified to run on-line with incoming text from different sources, it is ideally suited for implementation on personal computers with limited memory for RSVP reading of texts via telephone or satellite news and information services. In addition, several personal computer manufacturers are now selling in increasing numbers small, portable computers that have only a few (1 to 5) display lines. Page presentation of text on these computers is quite limited, and RSVP would provide an ideal text-presentation mode for these minidisplays.

\section{REFERENCES}

Clark, H. H., \& Clark, E. V. (1977). Psychology and language: An introduction to psycholinguistics. New York: Harcourt Brace Jovanavich.

CockuIN, T. G. (1983). Sensory and linguistic determinants of optimal text segments in RSVP reading. Unpublished master's thesis, University of Kansas, Lawrence.

Cocklin, T. G., WARD, N. J., CheN, H.-C., \& Juola, J. F. (1984) Factors influencing readability of rapidly presented text segments. Manuscript submitted for publication.

JUST, M. A., \& CARPENTER, P. A. (1980). A theory of reading: From eye fixations to comprehension. Psychological Review, 87, 329-354.

RAYNER, K. (1978). Eye movements in reading and information processing. Psychological Bulletin, 85, 618-660.

WINOGRAD, T. (1972). Understanding natural language. Cognitive Psychology, 3, 1-191.

Appendix A

Parsing Subroutine-FORTRAN

\section{SOBROOTIIE PARSE}

TEIS ROUTIME IS DESTGMED TO PARSE TEXT

ITTO A PBRASE STROCTURE USING PUNCTUATION

AND FUNCTIOH WORDS. TEZ PARSER ALSO EXAMINS

TRE PARSED TEXT AND ADJUSTS THE PARASES FOR LENGT

SO TRI THET MAY BE BETTRR UTILIZED IN THE RSVP

NEADING PORHAT

THIS ROUTINE UAS URITTEN IN 1983 BY

MTCEART $A$. GZARAAS FOR USE ON A DEC

PDP 11/03 MIRI-COMPUTER.

INPUT TO THIS ROUTINE COKE BY HAY OF THE

THO COROFO BLOCKS: WOROS AND TEXT.

wORDS-

WRD- ARRAT CONTAIRING THE LIST OF FONCTION WORDS WHICH WERE READ IN AN STORED IN A TREE STRUCTURE DY ANOTHER SUBROUT INE

RT,LT- RIGHT AND LEFT POINTERS FOR THE TREE STRUCTURE

TEXT-

TIT- ARRAT CONTAINING TEXT TO BE PARSED

DVEC- ARRAY NOT UTILIZED IN THIS SUBROUTINE

TSIZE- INTEGER NURBER OF CRARACTERS IN TXT

COMON/WORDS/ WRD, RT, LT

COMON/TEXT/ TXT, DVEC, TSIZE

COMSON/TEST/ TXT, DVEC, ISIZE
LOGICAL"I DVEC(60),TXI $(9500), 2, \mathrm{WRD}(110,10)$

IYTE PER, QHARX, BURR, COK, SEKCOL, STAR

BTTE BLAMK, $\triangle P O S$, PARN, COL, QT

INTEGER FLG, PT, PTT, TSIZE, RT(110), LT(110)

INTEGER I, J, ONT, FT, FTT, CNT2 , BR, PT2, FLC2 , FLC3

DeTe

DATA PARA/"051/, COL/"072/

DATA PARA/"051/, COL/"072/

OATA PER/"056/,QMARK/"O77/, EMARR/"041/

DATA COM/"054/.SEMCOL/"073/,STAR/"*'/

PASS ORE OP THE PARSER PIND AND MARK PUNCTUATION BOUNDRIES WITH A STAR

PONCTUATION OTHER THAN PERIODS AND LEFT PARENS

ARE MARRED TO THE TMEDDLTE RIGHT IF A BLANK SPACE

IS ATATLABLE, OTRERHISE NO MARR IS MADE.

IS ATAILABLE, OTHERHISE NO MARR IS MADE.

LEFT PARENS ARE MARKED TO THETR TMMEDLATE LET TO

BLANR SPACE IS AVATLASLE. PERIODS ARE MARXED TO

THEIR IMEDUTE RICHT IF A BLANR SPACE IS AVA ILABLE,
AND IF NEITHER OF THE TWO CHARACTERS PRECEDING THE
PERIOD ARE CAPITALIZED.

Do $5, I=1$, TSI2E

$2-T X T(I)$

IF (2.Ge."101) coto

IF (2.8Q.PER.AND.TXT(I-1).LT."133.AND. TXT(I-1),GT."100) coto

IF (2.BQ.PER.AND.TXT(I-2).LT."133.AND.IXT(I-2).GT."100) COTO

IF (2.EQ.PER.OR.2.EQ.QMARR.OR.2.EQ. DMARK) COTO 7

IF (2.EQ. COM.OR, Z,EQ.SEHCOL.OR.2.8Q.PARH.OR.Z.EQ.COL) COTO 7

IF (Z.BQ.QT.AND.TXT(I-1),BQ.BLANK) TXT (I-1)-STAR

IF (2.EQ.QT .AND. TXT $(I+1)$.EQ.BLANR ) TXT $(I+1)=$ STAR

coto 5

$I=1+1$

IF (TXT (I).NE. BLANR) GOTO 5

$\operatorname{TXT}(I)=S T A R$

COHTINUE

NON HE START TRE FONCTION WORD SEARCB.

WHEN WE FIND A MON-FUNCTION WORD POLLONED BY

A FUNCTION WORD WE PARSE BETWEEN THEM

FLG2 $=0$

TLG $=0$

TT=1

are-1

Goto 13

FLG=1

IF(FLG2.EQ.0) GOTO 13

$\operatorname{TXI}(\mathrm{FT})-\mathrm{TXT}(\mathrm{FT})-" 40$

PLC2 $=0$

CNT $=0$

$T=B R$

IF $(T X T(F T) . E Q . S T A R)$ FLG=0

Z-TXI ( $(8 T)$

IF (2.GE."101) GOTO 14

IF(2.LE."071.AND.Z.GE."060) GOTO 14

$B R=B R+1$

GOTO 13

PT2-1

$\mathrm{CNT}=\mathrm{CNT}+1$

$\mathrm{BR}-\mathrm{BK}+1$

IF ( $B R . G E$.

Z-TXT(BX)

IF (Z.LT." 101 .AND.Z.NE.APOS) COTO 25

GoTo 15

IF (CNT,GE,L1) GOTO 12

IF (TXT(FT) .GE."141) GOTO 30

FLG2 $=1$

$\operatorname{TXT}$ (FT) $-\operatorname{TXT}($ FT ) +" 040

$3=1$

If (CNT.EQ.12) GOTO 300

IF (TXI (FT).NE.WRD (PT2,J)) COTO 110

$P T=P T+1$

IP (PT.EQ.BK.AND.WRD(PT2,J+1),LT."141) GOT0 300

$\mathrm{CNT}=\mathrm{J}+\mathrm{CNT}+1$
$\mathrm{COTO}$

GOTO 31

IF (TXI (PT).LT.WRD (PT2,J)) GOTO 115

PT2-RT (PT2)

IF (PT2.EQ.0) COTO 12

coto 30

PT2-LT (PT2)

IF (PT2.EQ.0) GOTO 12

COTO 30

C

IF (FLC.EQ.0) COTO 303

IF (TXT (FT-1), BQ.BLANK.OR.TXT(FT-1) .EQ.STAR) GOTO 310 $T T-\pi-1$

310

IXT $(F T-1)=S T A R$

FLG $=0$

IT

IF (FLC2.EQ.0) COTO 301

$\operatorname{TXT}(\mathrm{FT})-\mathrm{TXT}(\mathrm{FT})-" 040$

PLG2 $=0$

$\operatorname{coto} 13$

THE THIRD AMD FINAL PASS OF THE PARSER CHECKS

THE PREVIOUSLY PARSED TEXT FOR UNIT SIZE.

ANY UNIT LARGER THAN 20 CHARACTERS IN LENGTH IS 

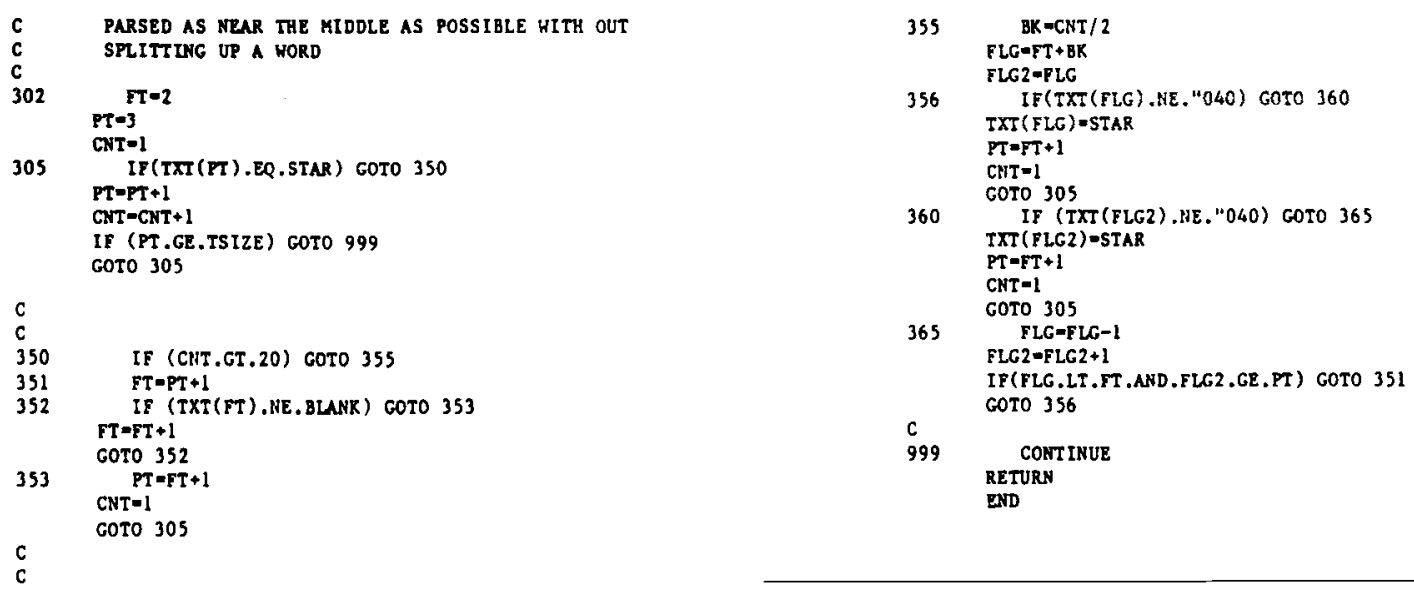

\section{Appendix B}

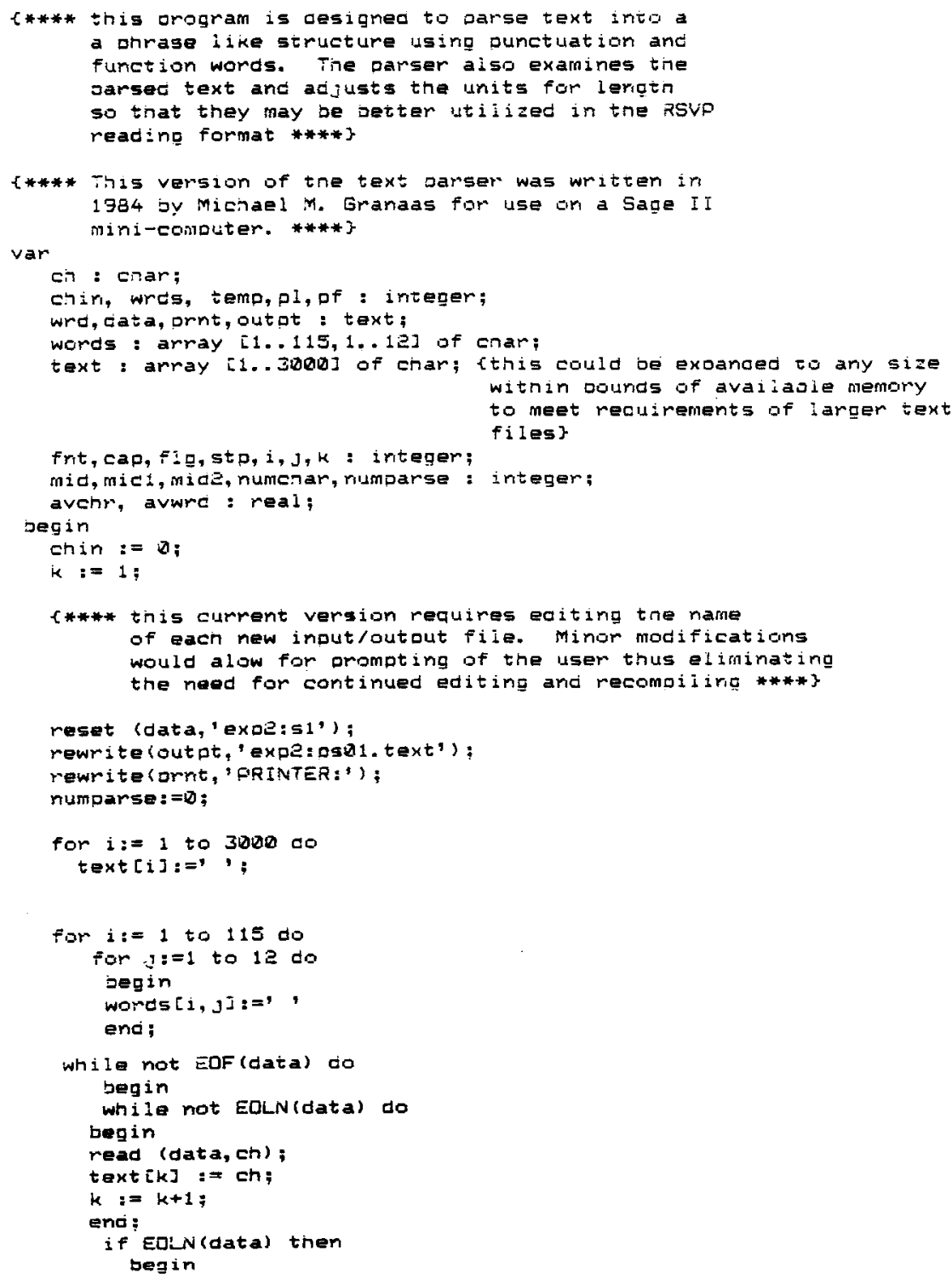




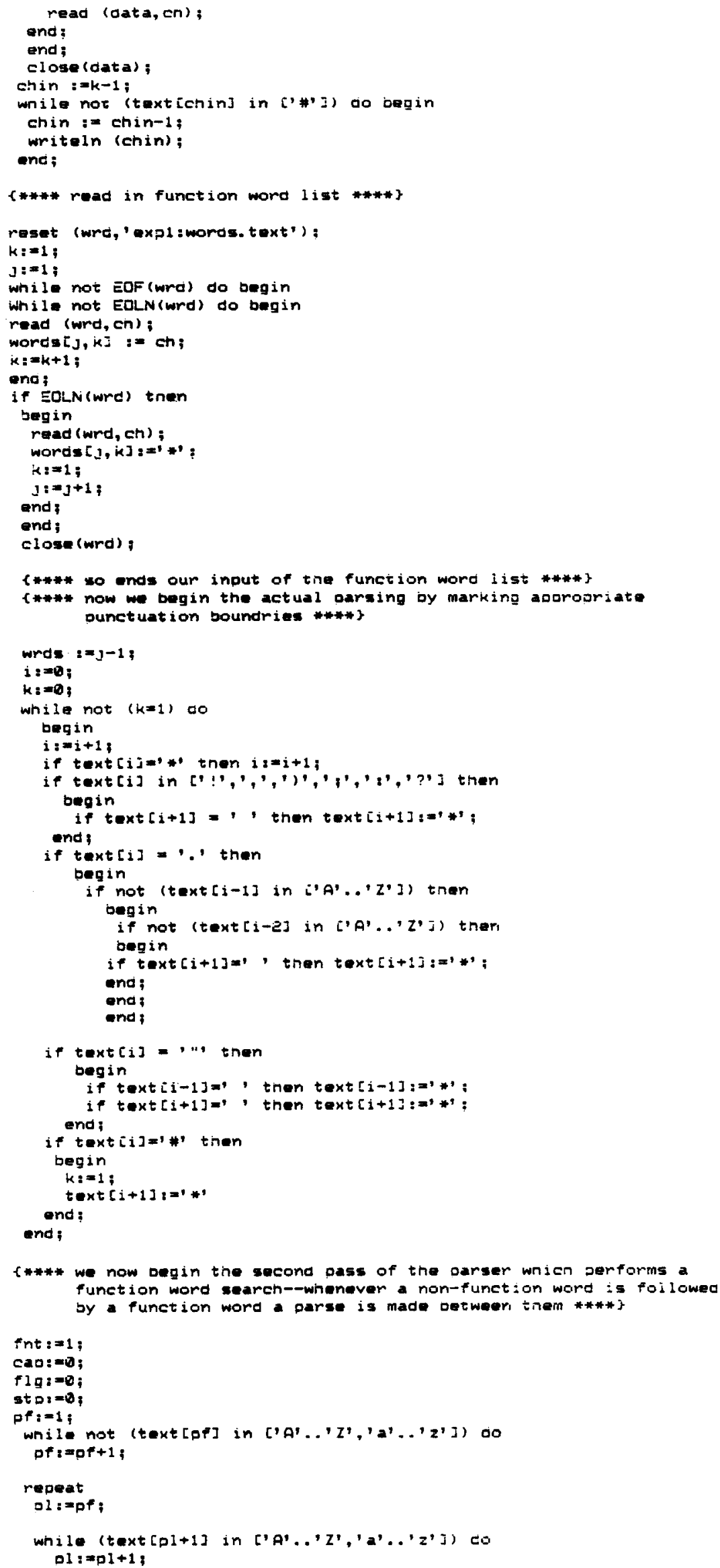




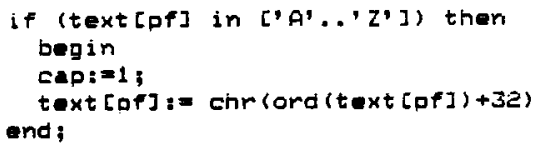




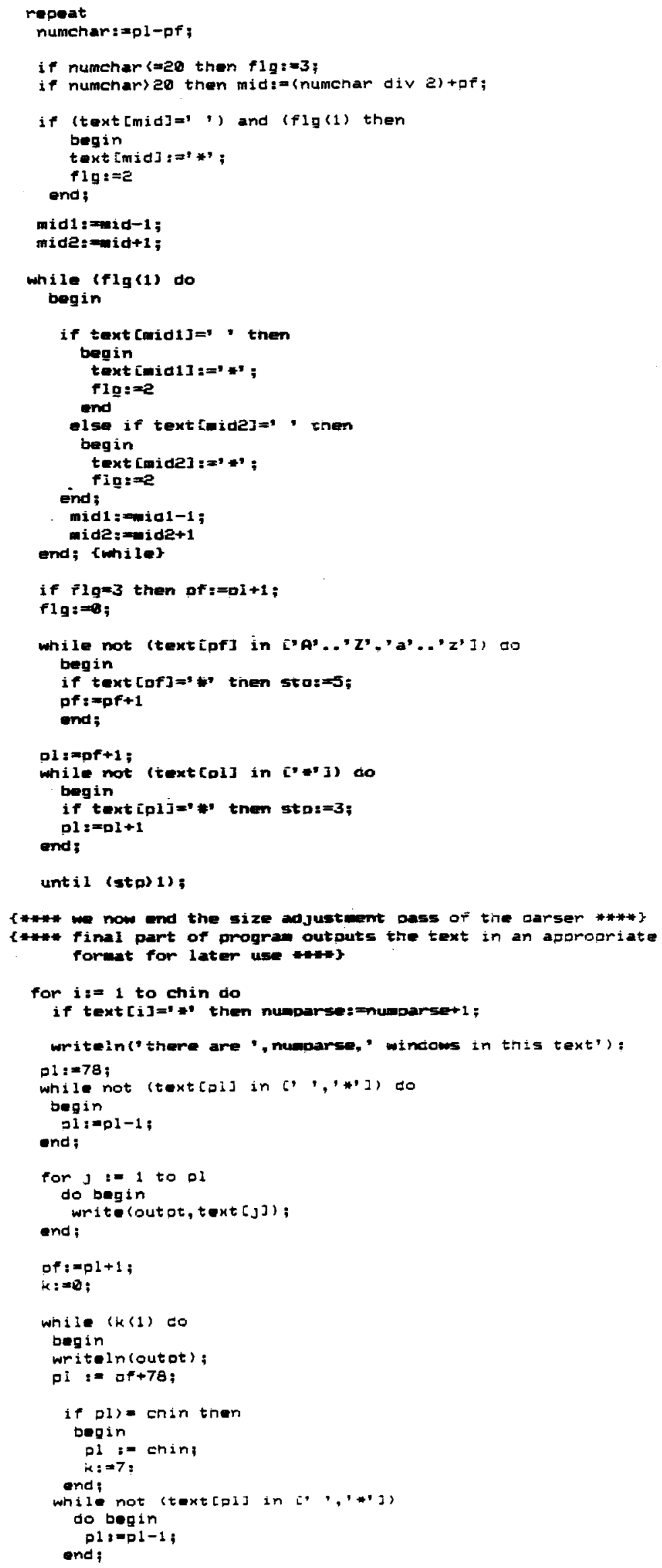




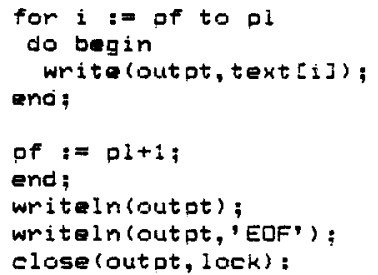

Appendix C

Function Words

\begin{tabular}{|c|c|c|c|}
\hline a & can & nor & what \\
\hline about & concerning & of & whatever \\
\hline above & could & off & when \\
\hline across & dare & on & where \\
\hline after & despite & once & which \\
\hline against & do & onto & whichever \\
\hline all & during & or & while \\
\hline although & except & ought & who \\
\hline amid & following & our & whoever \\
\hline amidst & for & over & whom \\
\hline amoung & from & past & whose \\
\hline an & had & regarding & why \\
\hline and & have & shall & will \\
\hline are & he & she & with \\
\hline around & how & should & within \\
\hline as & I & since & without \\
\hline at & if & so & would \\
\hline be & in & than & yet \\
\hline because & including & that & you \\
\hline before & into & the & under \\
\hline behind & is & though & underneath \\
\hline below & it & through & unless \\
\hline beneath & like & till & until \\
\hline besides & may & to & upon \\
\hline between & might & toward & versus \\
\hline beyond & must & was & via \\
\hline but & near & we & \\
\hline by & need & were & \\
\hline
\end{tabular}

